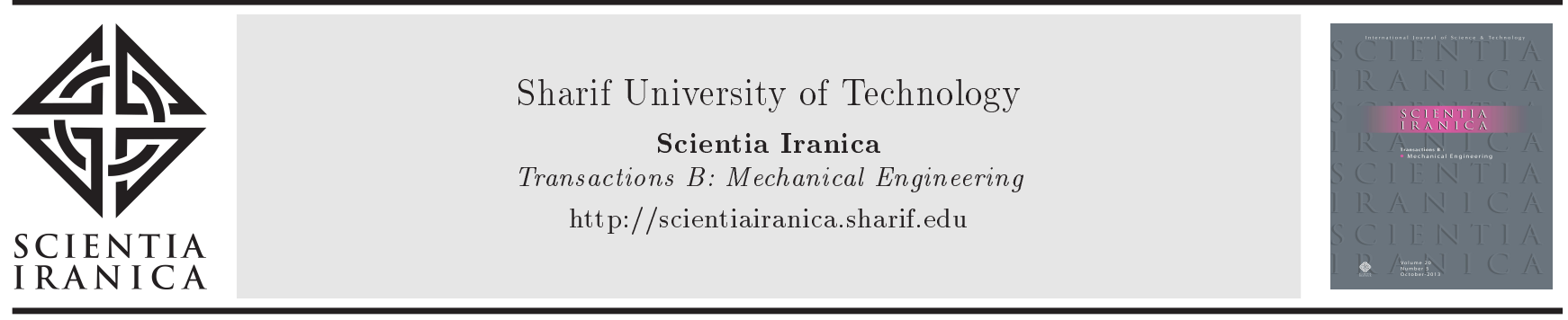

Research Note

\title{
A numerical model for predicting hepatocytes ureagenesis and its related inborn enzyme deficiencies: Case studies
}

\author{
F. Sharifi, B. Firoozabadi*, M.S. Saidi, and K. Firoozbakhsh \\ Department of Mechanical Engineering, Sharif University of Technology, Tehran, Iran.
}

Received 9 November 2015; received in revised form 17 June 2017; accepted 15 January 2018

\section{KEYWORDS}

Microchannel;

Hepatocyte;

Liver;

Urea;

Ammonia;

Urea deficiencies.

\begin{abstract}
One important functionality of liver cells is ammonia detoxification and urea production. In this study, a numerical model of the urea cycle in hepatocytes was developed. Navier Stokes and convection equations were employed to study the process of ammonia elimination and urea production using a microfluidic channel. The concentration of urea and ammonia throughout the channel was obtained. Furthermore, the urea cycle was modelled with respect to its four main enzymes. This resulted in twelve rate equations that were solved to determine the concentration of each metabolite participating in the urea cycle. Application of results implied common disorders such as hyperammonemia types I and II and argininosuccinicaciduria types I and II. Result of this study indicated that there is $80 \%$ chance of a reduction in concentration of citrulline, argininosuccinate, arginin, carbamoyl phosphate, phosphate and fumarate in hyperammonemia type II. A 10-fold increase of argininosuccinate concentration was observed in both argininosuccinicaciduria types I and II. The predicted result may be useful in better understanding and controlling of metabolite deficiencies in patient abnormalities.
\end{abstract}

(C) 2019 Sharif University of Technology. All rights reserved.

\section{Introduction}

Liver is a vital organ located in the right part of the abdomen cavity. Liver plays a substantial role in human's protein production and blood clotting, glucose, nitrogen, iron metabolisms, ammonia detoxification, and urea production [1].

Ammonia, generated from metabolism of amino acids in the body, is a very toxic material and should be eliminated from the circulation system. Liver plays a substantial role in ammonia elimination. In fact,

\footnotetext{
*. Corresponding author. Tel.: +982166165683; Fax: +982166000021

E-mail addresses: Sharifi.fatemeh@gmail.com (F. Sharifi); Firoozabadi@sharif.edu (B.Firoozabadi)
}

it converts ammonia into a water-soluble compound named urea which in turn is removed by the kidney [1]. Due to its importance, urea production is considered one of the factors determining hepatocytes' survival parameter.

Many researchers tend to investigate urea production numerically. Kuchel et al. [2] simplified urea cycle based on its four main participating enzymes. Time variation of related metabolites' concentration was obtained; thereupon, some inborn errors of metabolism pertaining to urea cycle were investigated. Their presented simulation showed that a numerical method would present a reliable potential in predicting metabolites concentration in different conditions such as enzyme deficiencies, inborn errors, etc. Kohn et al. [3] simulated ureagenesis in a flowchart-like model. They presented graphical software through which they could model urea metabolism in human body and predicted 
the response of this cycle to different metabolic inputs such as inborn errors. Maher et al. [4] also studied urea cycle numerically in which they separated reactions that take place in mitochondria from cytoplasm. Ohno et al. [5] modelled ammonia metabolism in a hepatic sinusoid based on metabolic reactions, which took place in a single cell. They tried to make a hepatic porto central axis by connecting their computational hepatic cells and mimicking histological structure of the liver lobule.

Spatial distribution of metabolites in the ureagenesis was not considered in previous studies. In reality, hepatic cells are arranged along the porto central channel, named sinusoid. Therefore, due to this cellular configuration, ureagenesis has gradients along the hepatic sinusoid.

In previous models, either total ureagenesis gradient has not been taken into consideration or gradient inside the porto central axis has been modelled using simple mathematical equations; besides, the gradient of the metabolites was not considered in their simulations.

Microfluidic systems lead to a better understanding of cellular functions since these channels are better at mimicking mechanisms occurring at cellular environments. Both experimental $[6,7]$ and numerical $[8,9]$ researches have been conducted on these applications of microfluidics. A structural form of human liver is composed of sinusoids along which various vital metabolisms occurred. Sinusoids can be considered as a microchannel in which liver cells are located along the border of the channel. In order to model ureagenesis, a hepatic sinusoid is modelled as a micro channel along which metabolites are transported. In the first step of this study, urea generation produced by hepatocyte monolayer in a rectangular microfluidics is modelled. Navier-Stokes equations along with convectiondiffusion equations of species are solved over the whole microfluidic domain. Two transporter models are also considered for transport of ammonia and urea. Twelve differential equations concerning metabolites including four pivotal enzymes, i.e., ornithine transcarbamoylase, argininosuccinate synthetase, arginerinosuccinase, and arginasedescribeurea generation of the hepatocyte, are inserted as flux boundary conditions. Thanks to this simulation, the precise concentration of each metabolite is obtained along the channel. Having established an in silico model of ureagenesis in the microfluidic channel, different metabolic disorders pertaining to the urea cycle in the body can be simulated. These disorders are named according to the deficiencies they cause or lack of related metabolites, i.e., carbamoyl phosphate deficiency, argininosuccinicaciduria, and argininemia. Most of these deficiencies can be detected in inborns appearing to be healthy after birth. Since the urea cycle is the main way of ammonia detoxification, any disorder in this cycle could increase the concentration of the ammonia in the body and cause hyperammonemia, whereupon if these enzymes deficiencies are not treated, the patient will die while there is no well-documented cure for them [2]. In this paper, a precise prediction of metabolites participating in the urea cycle through a computational modelling in different metabolic situations is presented. Predicted results are useful in better comprehending, controlling and managing the effects of metabolite deficiencies on overall metabolic behavior in hepatocytes' urea cycle.

This model also provides a useful tool for a better understanding of the nitrogen metabolism in hepatocytes, influx, and efflux of the metabolites in both hepatic cells and sinusoids as well as their dispersion in sinusoid. With the aid of this model, different urea disorders, effects of the drugs and metabolites on the entire cycle for each individual can be predicted. Therefore, researchers as well as physicians would have a numerical lab in order to test and verify different parameters and their side effects on hepatic ureagenesis. This would also minimize the need for physical testing.

\section{Mathematical method}

The width and length of the microchannel in this simulation are chosen in a way that the microfluidic channel resembles the average unit of hepatic porto central axis. The channel dimensions are given in Table 1. Similar to hepatic sinusoids, cells are lying along the channel. It is assumed that a layer with the thickness of one cell exists at the bottom wall of the microchannel. The

Table 1. Values of the used parameters in the present simulation.

\begin{tabular}{ll}
\hline \multicolumn{1}{c}{ Parameters } & \multicolumn{1}{c}{ Value } \\
\hline Width of micro channel $(w)$ & $150 \mu \mathrm{m}$ \\
Height of micro channel $(h)$ & $50 \mu \mathrm{m}$ \\
Average inlet velocity $\left(U_{0}\right)$ & $0.001 \mathrm{~m} / \mathrm{s}$ \\
Ammonia diffusion coefficient $\left(D_{\mathrm{NH}_{4}}\right)[10]$ & $10^{-11} \mathrm{~m}^{2} / \mathrm{s}$ \\
Urea diffusion coefficient $\left(D_{\text {Urea }}\right)[10]$ & $10^{-11} \mathrm{~m}^{2} / \mathrm{s}$ \\
Ammonia inlet concentration $\left(C_{0 \mathrm{NH}_{4}}\right)[10]$ & $6 \times 10^{-6} \mathrm{~mol} / \mathrm{m}^{3}$ \\
Urea inlet concentration $\left(C_{0 \text { Urea }}\right)[10]$ & $0 \mathrm{~mol} / \mathrm{m}^{3}$ \\
\hline
\end{tabular}




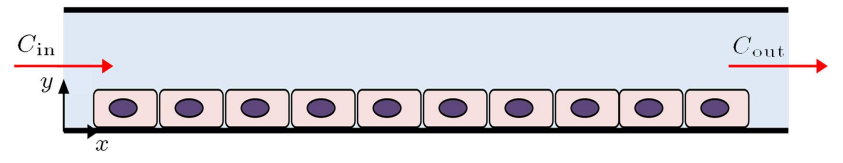

Figure 1. Schematic of the microfluidic device used in the simulation.

configuration of the cells in the microfluidic devices is shown schematically in Figure 1. The mathematical procedure can be divided into extracellular and subcellular modelling [5]. In the extracellular section, fluid flow distribution along the microchannel is obtained using unsteady two-dimensional continuity and Navier-Stokes equations [11]. These equations for incompressible fluid are as follows:

$$
\begin{aligned}
& \nabla \cdot \vec{u}=0 \\
& \rho\left(\frac{\partial \vec{u}}{\partial t}+\vec{u} \cdot \nabla \vec{u}\right)=-\nabla p+\mu \nabla^{2} \vec{u},
\end{aligned}
$$

where $\vec{u}, p, \rho$, and $\mu$ are fluid velocity, pressure, density, and viscosity, respectively. The bulk of the fluid in the extracellular domain is assumed to behave like Newtonian fluids.

The inlet velocity (Figure 1) is defined as follows:

$$
\vec{u}=U_{0} \cdot \vec{n} .
$$

$U_{0}$ is fluid velocity at the entrance of the channel, and $\vec{n}$ is the normal unit vector at this boundary. At the outlet, it is assumed that the velocity has no changes in the flow direction so that exit flow is fully developed and can be described as follows:

$$
\frac{\partial \vec{u}}{\partial x}=0 .
$$

The no-slip boundary condition is applied to upper and lower walls of the micro channel, that is:

$$
\vec{u}=0 \text {. }
$$

Once fluid flow distribution is determined, the velocity is applied to mass transfer equations. In the extracellular section, only concentration distribution of the ammonia and urea is calculated throughout the microfluidic channel. Since the concentration of the metabolites is considered to be diluted, the fluid flow distribution will not be affected. The following unsteady convection-diffusion equations are solved for both ammonia and urea:

$$
\frac{\partial C_{i}}{\partial t}+\nabla \cdot\left(-D_{i} \vec{\nabla} C_{i}+C_{i} \vec{u}\right)-R_{i}=0, \quad i=1,2 .
$$

In the above equation, index $i$ refers to the related metabolites, i.e., ammonia and urea, and $C_{i}, R_{i}$, and $D_{i}$ represent their concentration, reaction equation, and diffusion coefficient, respectively [12].
At the inlet, the boundary condition is:

$$
C_{i}=C_{0, i}, \quad i=1,2,
$$

where $C_{0, i}$ denotes the inlet concentration for ammonia and urea. The outlet boundary condition for the aforementioned concentration is defined as follows:

$$
\frac{\partial C_{i}}{\partial x}=0, \quad i=1,2 .
$$

The wall boundary condition in the convectiondiffusion equation, described below, is just applied to the upper wall of the channel:

$$
\frac{\partial C_{i}}{\partial y}=0, \quad i=1,2 .
$$

The boundary condition related to the lower wall of channel correlates with the ammonia and urea concentration. As ammonia enters the cells, the hepatocytes convert into urea. Then, urea will be excreted in the channel. Since fluid velocity is zero at this boundary, the flux boundary condition is determined as follows:

$$
\frac{\partial C_{i}}{\partial t}+\nabla \cdot\left(-D_{i} \nabla C_{i}\right)=R_{i}, \quad i=1,2 .
$$

Urea generation occurs at a subcellular level. The rate of urea production is dependent on many factors such as time, position of the cell along the microchannel, concentration of related metabolites, activities of participating enzymes, etc.

Ammonia permeates into and urea excretes from the hepatocyte through their respective transporters. Overall, metabolic transportation is schematically shown in Figure 2. These mechanisms are also modelled using reaction rate equations:

$$
\frac{\partial \mathrm{NH}_{4-t p}}{\partial t}=k_{\mathrm{NH}_{4-t p}}\left(C_{\mathrm{NH}_{4}}-\mathrm{NH}_{4-t p}\right)
$$

for ammonia and:

$$
\frac{\partial U_{t p}}{\partial t}=k_{U_{t p}}\left(U-U_{t p}\right)
$$

for urea transportations.

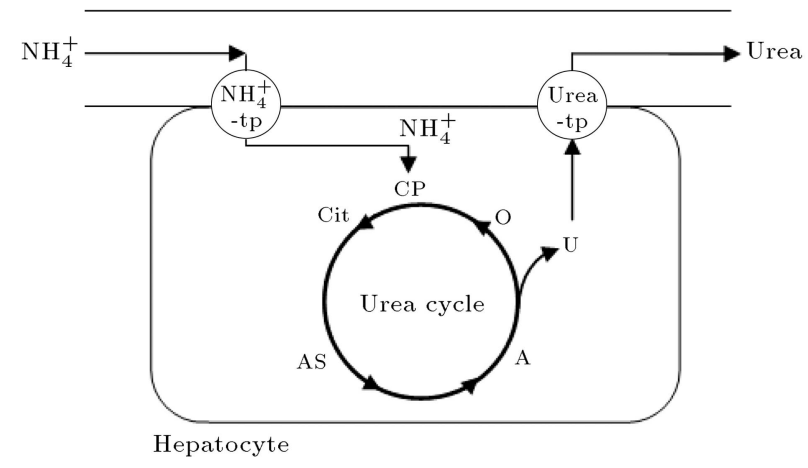

Figure 2. Schematic of urea generation in hepatocytes. 
Urea cycle is briefly described by its four main participating enzymes [2]. These enzymes are Ornithine transcarbamoylase, argininosuccinate synthetase, argininosuccinase, and arginase. Their names are chosen based on the reaction in which they participate. Ammonia first enters the hepatic cells; thereafter, together with carbamoyl phosphate synthetase, carbamoyl phosphate is produced. Then, ornithine transcarbamoylase and ornithine yield phosphate and citruline, which in turn serves as a substrate for argininosuccinate synthetase. In the production of argininosuccinate, ATP is consumed. Fumarate and arginine are the result of the third enzymatic reaction. In the last part, arginase catalyzes arginine and produces urea and ornithine. Urea is then excreted from hepatic cells into sinusoids, and ornithine is utilized again in the ornithine transcarbamoylase reaction [13]. The overall urea cycle is illustrated in Figure 3. Since the names of the metabolites participating in urea cycle are long, for the sake of simplicity, their abbreviations are used throughout this simulation. The full names, formulas, and related abbreviations of the metabolites are given in Table 2 .

As previously mentioned, the urea cycle can be categorized based on its four main participating enzymes:

I. Ornithine transcarbamoylase: This reaction, shown in Figure 4, is of the type of reversible Bi$\mathrm{Bi}$ form. The corresponding rate equation is given by [2] Eq. (13) as shown in Box I. Values, given in Table 3, are selected within realistic ranges.

II. Argininosuccinatesynthetase $\left(E_{2}\right)$ : Argininosuccinate has three reactants in the forward (C, ATP, and ASP) and backward (PP, AMO, and AS)

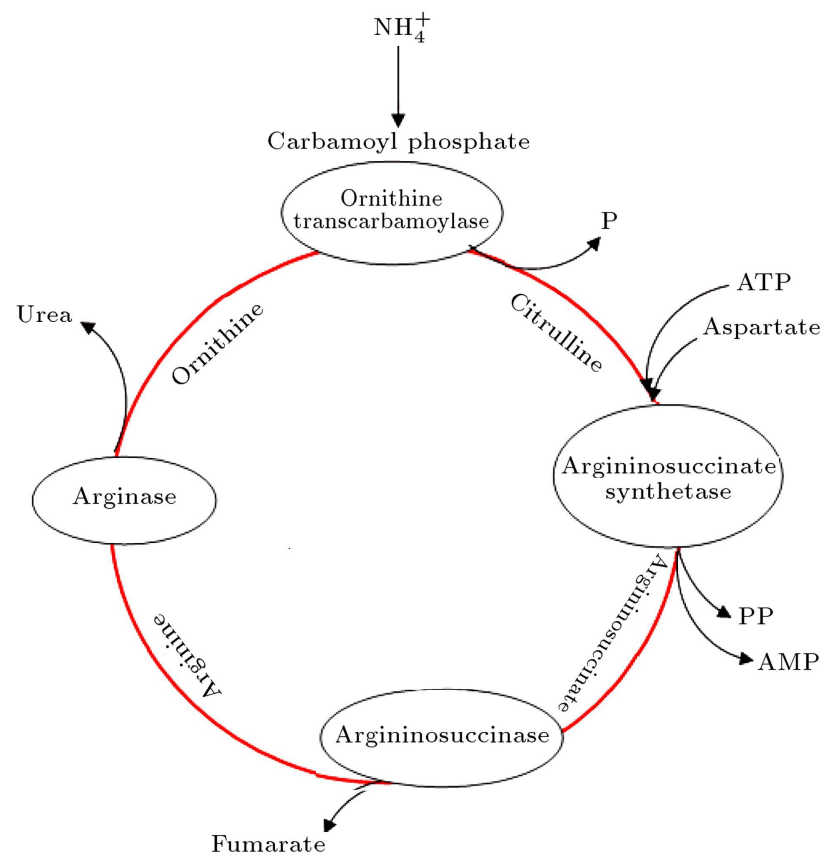

Figure 3. Schematic of the urea cycle in the hepatocyte. Enzymes are shown in an elliptical configuration.

reactions. Therefore, the mechanism is of Ter Ter reaction type. The schematic of this reaction is illustrated in Figure 5.

According to Figure 5, the reaction rate for the above TerTer mechanisms is given by [2] Eq. (14) as shown in Box II.

III. Argininosuccinate: Since there are one and two reactant(s) in the forward and backward reactions, shown in Figure 6, respectively, the form of this rate equation is Uni $\mathrm{Bi}$ format, which has the reaction rate of [2]:

Table 2. Compound names, formulas, and abbreviations used in this study [14].

\begin{tabular}{cll}
\hline Abbreviation & \multicolumn{1}{c}{ Full name } & \multicolumn{1}{c}{ Compound formula } \\
\hline C & Citrulline & $\mathrm{C}_{6} \mathrm{H}_{13} \mathrm{~N}_{3} \mathrm{O}_{3}$ \\
AS & Argininosuccinate & $\mathrm{C}_{10} \mathrm{H}_{18} \mathrm{~N}_{4} \mathrm{O}_{6}$ \\
A & Arginin & $\mathrm{C}_{6} \mathrm{H}_{14} \mathrm{~N}_{4} \mathrm{O}_{2}$ \\
O & Ornithine & $\mathrm{C}_{5} \mathrm{H}_{12} \mathrm{~N}_{2} \mathrm{O}_{2}$ \\
U & Urea & $\mathrm{CH}_{4} \mathrm{~N}_{2} \mathrm{O}$ \\
CP & Carbamoyl phosphate & $\mathrm{CH}_{2} \mathrm{NO}_{5} \mathrm{P}^{2-}$ \\
ATP & Adenosine triphosphate & $\mathrm{C}_{10} \mathrm{H}_{16} \mathrm{~N}_{5} \mathrm{O}_{13} \mathrm{P}_{3}$ \\
ASP & Aspartate & $\mathrm{C}_{4} \mathrm{H}_{7} \mathrm{NO}_{4}$ \\
PP & Pyrophosphate & $\mathrm{P}_{2} \mathrm{O}_{7}^{4-}$ \\
AMP & Adenosine monophosphate & $\mathrm{C}_{10} \mathrm{H}_{14} \mathrm{~N}_{5} \mathrm{O}_{7} \mathrm{P}$ \\
F & Fumarate & $\mathrm{C}_{4} \mathrm{H}_{4} \mathrm{O}_{4}$ \\
P & Phosphate & $\mathrm{PO}_{4}^{3-}$ \\
\hline
\end{tabular}




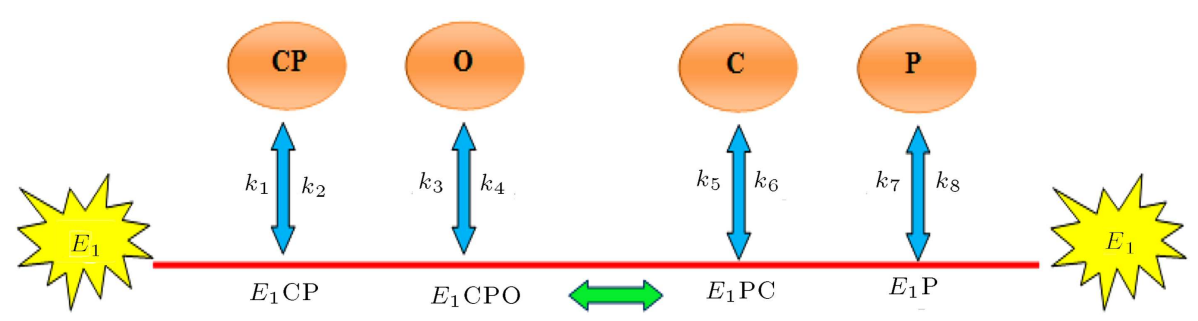

Figure 4. Ornithine transcarbamoylase reaction.

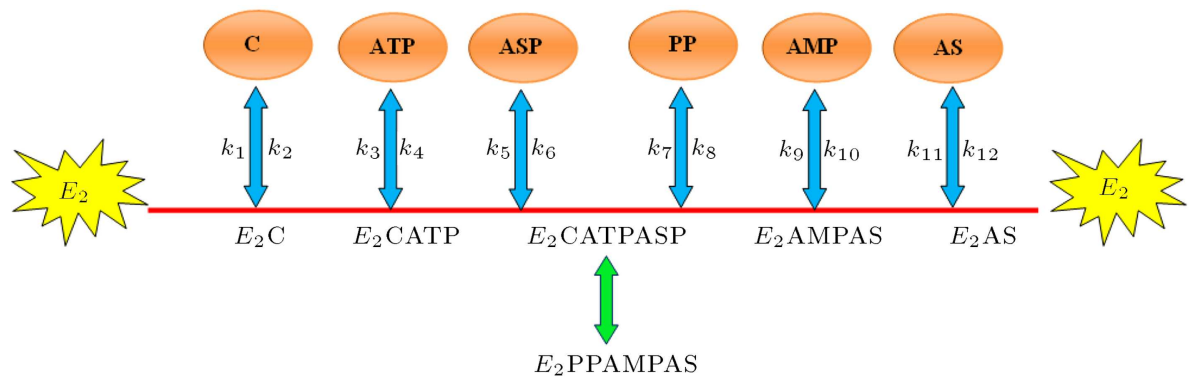

Figure 5. Reaction of argininosuccinatesynthetase.

$$
\begin{gathered}
v_{1}=\frac{\left\{k_{1} k_{2} k_{3} k_{4}[\mathrm{CP}][\mathrm{O}]-k_{2} k_{4} k_{6} k_{8}[\mathrm{P}][\mathrm{C}]\right\}\left[E_{1}\right]_{0}}{\left\{k_{2} k_{7}\left(k_{4}+k_{5}\right)+k_{1} k_{7}\left(k_{4}+k_{5}\right)[\mathrm{CP}]+k_{2} k_{8}\left(k_{4}+k_{5}\right)[\mathrm{P}]+k_{3} k_{5} k_{7}[\mathrm{O}]+k_{2} k_{4} k_{6}[\mathrm{C}]+\right.} \\
k_{1} k_{3}\left(k_{5}+k_{7}\right)[\mathrm{CP}][\mathrm{O}]+k_{6} k_{8}\left(k_{2}+k_{4}\right)[\mathrm{P}][\mathrm{C}]+k_{1} k_{4} k_{6}[\mathrm{CP}][\mathrm{C}]+ \\
\left.k_{1} k_{3} k_{6}[\mathrm{CP}][\mathrm{O}][\mathrm{C}]+k_{3} k_{5} k_{8}[\mathrm{O}][\mathrm{P}]+k_{3} k_{6} k_{8}[\mathrm{O}][\mathrm{P}][\mathrm{C}]\right\} .
\end{gathered}
$$

Box I

$$
\begin{aligned}
v_{2}=\frac{\left\{k_{1} k_{3} k_{5} k_{7} k_{9}[\mathrm{C}][\mathrm{ATP}][\mathrm{ASP}]-k_{2} k_{4} k_{6} k_{8} k_{10} k_{12}[\mathrm{PP}][\mathrm{AMP}][\mathrm{AS}]\right\}\left[E_{2}\right]_{0}}{\left\{k_{2} k_{4} k_{9} k_{11}\left(k_{6}+k_{7}\right)+k_{1} k_{4} k_{6} k_{8} k_{11}[\mathrm{C}][\mathrm{PP}]+k_{1} k_{4} k_{9} k_{11}\left(k_{6}+k_{7}\right)[\mathrm{C}]+k_{2} k_{5} k_{7} k_{9} k_{12}[\mathrm{ASP}][\mathrm{AS}]+\right.} \\
k_{2} k_{5} k_{7} k_{9} k_{11}[\mathrm{ASP}]+k_{1} k_{3} k_{6} k_{8} k_{11}[\mathrm{C}][\mathrm{ATP}][\mathrm{PP}]+k_{1} k_{3} k_{9} k_{11}\left(k_{6}+k_{7}\right)[\mathrm{C}][\mathrm{ATP}]+ \\
k_{1} k_{4} k_{6} k_{8} k_{10}[\mathrm{C}][\mathrm{PP}][\mathrm{AMP}]+k_{1} k_{5} k_{7} k_{9} k_{11}[\mathrm{C}][\mathrm{ASP}]+k_{3} k_{5} k_{7} k_{9} k_{12}[\mathrm{ATP}][\mathrm{ASP}][\mathrm{AS}]+ \\
k_{3} k_{5} k_{7} k_{9} k_{11}[\mathrm{ATP}][\mathrm{ASP}]+k_{2} k_{5} k_{7} k_{10} k_{12}[\mathrm{ASP}][\mathrm{AMP}][\mathrm{AS}]+k_{2} k_{4} k_{9} k_{12}\left(k_{6}+k_{7}\right)[\mathrm{AS}]+ \\
k_{1} k_{3} k_{6} k_{8} k_{10}[\mathrm{C}][\mathrm{ATP}][\mathrm{PP}][\mathrm{AMP}]+k_{1} k_{3} k_{5}\left(k_{7} k_{9}+k_{7} k_{11}+k_{9} k_{11}\right)[\mathrm{C}][\mathrm{ATP}][\mathrm{ASP}]+ \\
k_{1} k_{3} k_{5} k_{8} k_{11}[\mathrm{C}][\mathrm{ATP}][\mathrm{ASP}][\mathrm{PP}]+k_{2} k_{4} k_{6} k_{8} k_{11}[\mathrm{PP}]+k_{1} k_{3} k_{5} k_{7} k_{10}[\mathrm{C}][\mathrm{ATP}][\mathrm{ASP}][\mathrm{AMP}]+ \\
k_{2} k_{4} k_{6} k_{8} k_{10}[\mathrm{PP}][\mathrm{AMP}]+k_{3} k_{5} k_{7} k_{10} k_{12}[\mathrm{ATP}][\mathrm{ASP}][\mathrm{AMP}][\mathrm{AS}]+k_{2} k_{4} k_{6} k_{8} k_{12}[\mathrm{PP}][\mathrm{AS}]+ \\
k_{3} k_{6} k_{8} k_{10} k_{12}[\mathrm{ATP}][\mathrm{PP}][\mathrm{AMP}][\mathrm{AS}]+k_{2} k_{4} k_{10} k_{12}\left(k_{6}+k_{7}\right)[\mathrm{AMP}][\mathrm{AS}]+ \\
k_{2} k_{5} k_{8} k_{10} k_{12}[\mathrm{ASP}][\mathrm{PP}][\mathrm{AMP}][\mathrm{AS}]+k_{8} k_{10} k_{12}\left(k_{2} k_{4}+k_{2} k_{6}+k_{4} k_{6}\right)[\mathrm{P}][\mathrm{AMP}][\mathrm{AS}]+ \\
\left.k_{1} k_{3} k_{5} k_{8} k_{10}[\mathrm{C}][\mathrm{ATP}][\mathrm{ASP}][\mathrm{PP}][\mathrm{AMP}] . k_{3} k_{5} k_{8} k_{10} k_{12}[\mathrm{ATP}][\mathrm{ASP}][\mathrm{PP}][\mathrm{AMP}][\mathrm{AS}]\right\} .
\end{aligned}
$$


Table 3. Constants of each urea reaction rate equation [2].

$$
\begin{aligned}
& \text { Ornithine transcarbamoylase } \\
& k_{1}=1.7 \times 10^{7} \mathrm{M}^{-1} \mathrm{~s}^{-1} \\
& k_{2}=6.3 \times 10 \mathrm{~s}^{-1} \\
& k_{3}=2.1 \times 10^{6} \mathrm{M}^{-1} \mathrm{~s}^{-1} \\
& k_{4}=1 \times 10^{3} \mathrm{~s}^{-1} \\
& k_{5}=3 \times 10^{3} \mathrm{~s}^{-1} \\
& k_{6}=9 \times 10^{4} \mathrm{M}^{-1} \mathrm{~s}^{-1} \\
& k_{7}=2.6 \times 10^{3} \mathrm{~s}^{-1} \\
& k_{8}=5 \times 10^{5} \mathrm{M}^{-1} \mathrm{~s}^{-1} \\
& \begin{array}{l}
\text { Argininosuccinase } \\
\hline k_{1}=2.7 \times 10^{6} \mathrm{M}^{-1} \mathrm{~s}^{-1} \\
k_{2}=7 \times 10 \mathrm{~s}^{-1} \\
k_{3}=7.5 \times 10 \mathrm{~s}^{-1} \\
k_{4}=1.5 \times 10^{6} \mathrm{M}^{-1} \mathrm{~s}^{-1} \\
k_{5}=1.1 \times 10^{3} \mathrm{~s}^{-1} \\
k_{6}=7 \times 10^{5} \mathrm{M}^{-1} \mathrm{~s}^{-1}
\end{array} \\
& k_{1}=2.4 \times 10^{5} \mathrm{M}^{-1} \mathrm{~s}^{-1} \\
& k_{2}=2.3 \times 10 \mathrm{~s}^{-1} \\
& k_{3}=3.5 \times 10^{4} \mathrm{M}^{-1} \mathrm{~s}^{-1} \\
& k_{4}=1 \times 10 \mathrm{~s}^{-1} \\
& k_{5}=4.8 \times 10^{5} \mathrm{M}^{-1} \mathrm{~s}^{-1} \\
& k_{6}=1 \times 10 \mathrm{~s}^{-1} \\
& k_{7}=2 \times 10 \mathrm{~s}^{-1} \\
& k_{8}=8.9 \times 10^{5} \mathrm{M}^{-1} \mathrm{~s}^{-1} \\
& k_{9}=5 \times 10 \mathrm{~s}^{-1} \\
& k_{10}=6.4 \times 10^{5} \mathrm{M}^{-1} \mathrm{~s}^{-1} \\
& k_{11}=5 \times 10 \mathrm{~s}^{-1} \\
& k_{12}=1.7 \times 10^{5} \mathrm{M}^{-1} \mathrm{~s}^{-1} \\
& v_{3}=\frac{\left\{k_{1} k_{3} k_{5}[\mathrm{AS}]-k_{2} k_{4} k_{6}[\mathrm{~F}][\mathrm{At}]\right\}\left[E_{3}\right]_{0}}{\left\{k_{5}\left(k_{2}+k_{3}\right)+k_{1}\left(k_{3}+k_{5}\right)[\mathrm{AS}]+\right.} \\
& k_{2} k_{4}[\mathrm{~F}]+k_{6}\left(k_{2}+k_{3}\right)[\mathrm{A}]+ \\
& \left.k_{4} k_{6}[\mathrm{~A}][\mathrm{F}]+k_{1} k_{4}[\mathrm{AS}][\mathrm{F}]\right\} \text {. }
\end{aligned}
$$

Argininosuccinatesynthetase

\begin{aligned} & \multicolumn{1}{c}{ Arginase } \\ & \hline$k_{1}=1 \times 10^{7} \mathrm{M}^{-1} \mathrm{~s}^{-1} \\ & k_{2}=5.4 \times 10^{4} \mathrm{~s}^{-1} \\ & k_{3}=5.3 \times 10^{3} \mathrm{~s}^{-1} \\ & k_{4}=3 \times 10^{4} \mathrm{~s}^{-1} \\ & k_{5}=1 \times 10^{7} \mathrm{M}^{-1} \mathrm{~s}^{-1} \\ &$\hline\end{aligned}

IV. Arginase: The reaction of arginase in the urea cycle is irreversible. This reaction is depicted in Figure 7 , and its related rate equation is given by [2]:

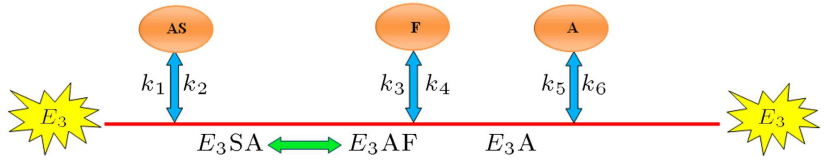

Figure 6. Schematic of argininosuccinate reaction.

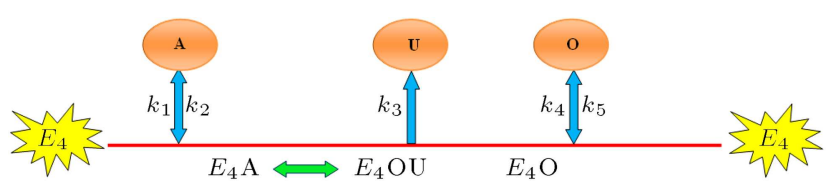

Figure 7. Schematic diagram of arginase reaction.

$$
v_{4}=\frac{k_{1} k_{3} k_{4}[\mathrm{~A}]\left[E_{4}\right]_{0}}{k_{4}\left(k_{2}+k_{3}\right)+k_{5}\left(k_{2}+k_{3}\right)[\mathrm{O}]+k_{1}\left(k_{3}+k_{4}\right)[\mathrm{A}]}
$$

For the above reaction equations, enzymes' activities have to be identified. Different urea enzyme's activities are reported in the literature [15-17]. Schimke [15] declared that enzymes' quantity in the urea cycle of a person is related to amount of the protein intake during a day. He also considered other factors affecting urea cycle enzymes and implied that different physiological states, such as starvation and corticosteroid, would cause an increase in all enzymes participating in ureagenesis [16]. Stanbury et al. [18] stated that adrenalectomy and arginine-free diet of the patient enhance these enzymes. In this study, the activity of each enzyme is chosen according to the activities reported in the study carried out by Kuchel et al [2]. These activities are given in Table 4 .

Eqs. (17)-(28) give concentration of metabolites participating in the urea cycle. These differential equations are coupled and must be solved simultaneously [2]:

$$
\begin{aligned}
& \frac{d[\mathrm{C}]}{d t}=v_{1}-v_{2}, \\
& \frac{d[\mathrm{AS}]}{d t}=v_{2}-v_{3}, \\
& \frac{d[\mathrm{~A}]}{d t}=v_{3}-v_{4}, \\
& \frac{d[\mathrm{O}]}{d t}=v_{4}-v_{1}, \\
& \frac{d[\mathrm{U}]}{d t}=+v_{4}-k_{U_{t p}} \times U_{t p}, \\
& \frac{d[\mathrm{CP}]}{d t}=k_{\mathrm{NH}_{4}} \mathrm{NH}_{4-t p}^{+}-v_{1}, \\
& \frac{d[\mathrm{ATP}]}{d t}=k_{\mathrm{ATP}}^{*}[\mathrm{Y}]_{\mathrm{pool}}-v_{2},
\end{aligned}
$$


Table 4. Enzymes' activities participating in urea cycle [2].

\begin{tabular}{lccc}
\hline \multicolumn{1}{c}{ Enzyme } & $\begin{array}{c}\text { Total activity } \\
\text { (I. U./kg liver) }\end{array}$ & $\begin{array}{c}\text { Total enzyme } \\
\text { ( mg/kg liver) }\end{array}$ & $\begin{array}{c}\text { Concentration } \\
\text { ( mol/lit) }\end{array}$ \\
\hline Ornithine transcarbamoylase & $1.1 \times 10^{5}$ & $1.4 \times 10^{2}$ & $2.6 \times 10^{-6}$ \\
Argininosuccinatesynthetase & $1.4 \times 10^{3}$ & $3.5 \times 10^{2}$ & $4 \times 10^{-6}$ \\
Argininosuccinase & $5 \times 10^{3}$ & $2.2 \times 10^{2}$ & $2.2 \times 10^{-6}$ \\
Arginase & $9.2 \times 10^{5}$ & $5.1 \times 10^{2}$ & $8.9 \times 10^{-6}$ \\
\hline
\end{tabular}

Table 5. Initial concentration of metabolites used in this study [19].

\begin{tabular}{clc}
\hline Abbreviation & \multicolumn{1}{c}{ Full name } & Initial concentration \\
\hline C & Citrulline & $1 \times 10^{-7}$ \\
AS & Argininosuccinate & $1 \times 10^{-5}$ \\
A & Arginin & $1 \times 10^{-7}$ \\
O & Ornithine & $4.5 \times 10^{-4}$ \\
U & Urea & $1 \times 10^{-5}$ \\
CP & Carbamoyl phosphate & $1 \times 10^{-4}$ \\
ATP & Adenosine triphosphate & $1 \times 10^{-3}$ \\
ASP & Aspartate & $1 \times 10^{-3}$ \\
PP & Pyrophosphate & $1 \times 10^{-5}$ \\
AMP & Adenosine monophosphate & $1 \times 10^{-5}$ \\
F & Fumarate & $1 \times 10^{-5}$ \\
P & Phosphate & $1 \times 10^{-5}$ \\
\hline
\end{tabular}

$\frac{d[\mathrm{ASP}]}{d t}=k_{\mathrm{ASP}}^{*}[\mathrm{Y}]_{\text {pool }}-v_{2}$

$\frac{d[\mathrm{PP}]}{d t}=-k_{\mathrm{PP}}^{*}[\mathrm{PP}]+v_{2}$

$\frac{d[\mathrm{AMP}]}{d t}=-k_{\mathrm{AMP}}^{*}[\mathrm{AMP}]+v_{2}$,

$\frac{d[\mathrm{~F}]}{d t}=-k_{F}^{*}[\mathrm{~F}]+v_{3}$

$$
\frac{d[\mathrm{P}]}{d t}=-k_{P}^{*}[\mathrm{P}]+v_{1} .
$$

In order to solve the aforementioned ordinary differential equations, the initial concentration of each metabolite requires to be determined, and these values are given in Table 5 .

The amounts of ammonia consumption and urea generation are specified using Eqs. (21) and (22), respectively. Concentration difference of ammonia and urea between inside and outside of the hepatocytes is the reason for transmission of these metabolites into and out of the hepatic cells. In order to consider this effect, Eq. (10) is modified for ammonia and urea as follows:

$$
\begin{aligned}
\frac{\partial C_{\mathrm{NH}_{4}^{+}}}{\partial t} & +\nabla \cdot\left(-D_{\mathrm{NH}_{4}^{+}} \nabla C_{\mathrm{NH}_{4}^{+}}\right) \\
& =-k_{\mathrm{NH}_{4}^{+}}\left(C_{\mathrm{NH}_{4-t p}^{+}}-\mathrm{NH}_{4-t p}^{+}\right),
\end{aligned}
$$

$$
\frac{\partial C_{U}}{\partial t}+\nabla \cdot\left(-D_{U} \nabla C_{U}\right)=k_{U_{t p}} U_{t p}
$$

The overall procedure of the presented numerical simulation is illustrated in Figure 8. The first step is the calculation of velocity profile using Navier-Stokes equations. Afterwards, distribution of urea and ammonia in the channel is obtained by solving convection diffusion, transport, and urea cycle with regarding the aforementioned differential equations, simultaneously.

A finite-element code is developed for this timedependent simulation. Simulation is carried out by a computer featuring a core i7 CPU, 8 GB RAM. Different element sizes are used to compute ammonia concentrations in the channel. Figure 9 depicts variation of ammonia concentration versus total number of elements used within the channel. According to this figure, 60 triangular elements are sufficient for this study.

In order to validate the numerical procedure, first, a lumped model based on the presented model of Kuchel et al. [2] is developed. In the lumped model, spatial distribution of metabolites is considered to have negligible effect on the metabolite concentration. Therefore, the complicated partial differential equations governing the status of the metabolite system are simplified into zero-dimensional ordinary differential equations. Results of this simulation are given in Table 6, demonstrating acceptable compatibility to those of Kuchel et al. [2], especially at the beginning of the simulation. The difference of the obtained data from those of Kuchel et al. [2] is 


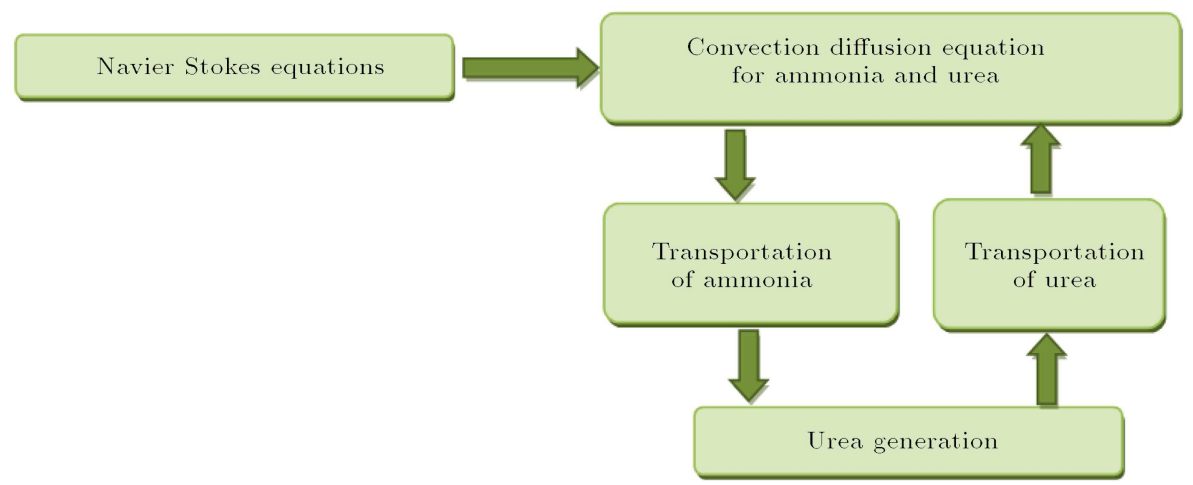

Figure 8. flowchart of the solution.

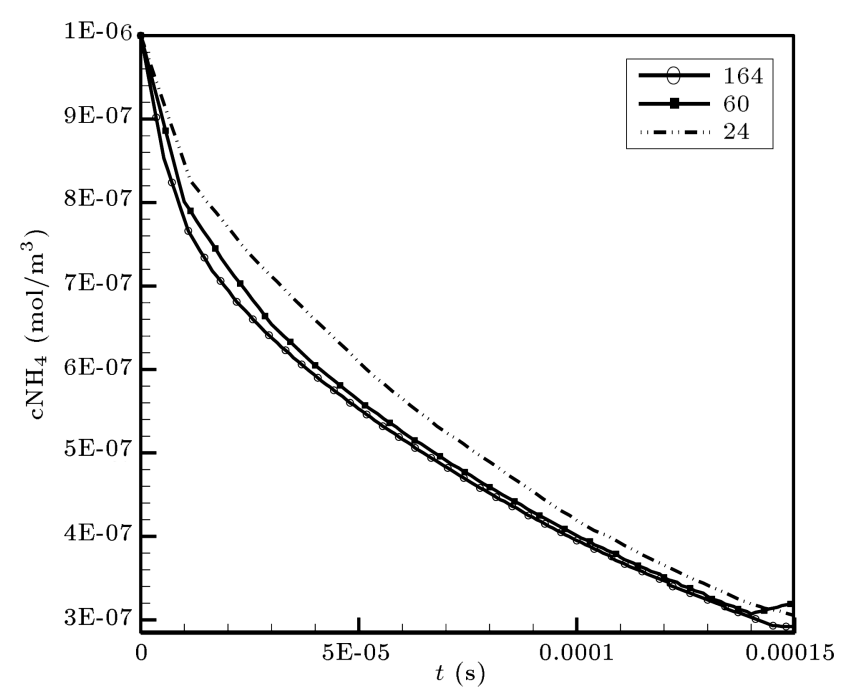

Figure 9. Grid study for this simulation. Ammonia concentrations across the channel are compared for different triangular grid numbers (24, 60, and 164).

due to the fact that, in the latter, all of the metabolite concentrations except for ornithine were set to zero. In [19], Kuchel et al. assumed different concentrations for each metabolite, which seemed to be closer to the normal value in the liver.

Table 6 shows the obtained results from the FEM code generated for predicting urea along with the results attained by Kuchel et al. [2] in the lump model. In addition to the results of variation of metabolites along a sinusoid, an improved model of Kuchel et al. [2] will be presented in which gradient of each participating metabolites is considered. This mimicking model is more similar to what happens inside the liver sinusoids.

\section{Results}

The fluid contains high ammonia concentration that enters the micro channel. The inlet concentration of ammonia was chosen based on previous reported experimental data [20]. Then, hepatocytes convert ammonia into urea. Inlet fluid velocity in the microfluidic device is set based on average blood velocity in the liver sinusoid and considered $0.001 \mathrm{~m} / \mathrm{s}$. In Figure 10, the velocity distribution in the micro channel is demonstrated. Due to low mainstream velocity,

Table 6. Comparison of different species concentrations with the respective concentrations of the species presented by Kuchel et al. [2]; data in parentheses are the obtained data from the present lumped simulation study.

\begin{tabular}{clll}
\hline \multirow{2}{*}{ Compound } & \multicolumn{3}{c}{ Concentration ( mol/lit) } \\
\cline { 2 - 4 } & \multicolumn{1}{c}{$\mathbf{1 0} \mathbf{~ s}$} & \multicolumn{1}{c}{$\mathbf{3 6 0} \mathbf{~ s}$} & \multicolumn{1}{c}{$\mathbf{6 0 0} \mathbf{~ s}$} \\
\hline O & $3.96 \mathrm{e}-4(4.50 \mathrm{e}-4)$ & $2.58 \mathrm{e}-4(4.50 \mathrm{e}-4)$ & $2.56 \mathrm{e}-4(4.50 \mathrm{e}-4)$ \\
C & $4.81 \mathrm{e}-5(4.8 \mathrm{e}-5)$ & $1.84 \mathrm{e}-4(1.82 \mathrm{e}-5)$ & $1.86 \mathrm{e}-4(1.82 \mathrm{e}-5)$ \\
AS & $9.31 \mathrm{e}-7(2.32 \mathrm{e}-8)$ & $2.40 \mathrm{e}-6(2.97 \mathrm{e}-8)$ & $2.44 \mathrm{e}-6(2.97 \mathrm{e}-8)$ \\
A & $3.9 \mathrm{e}-7(1.13 \mathrm{e}-8)$ & $8.82 \mathrm{e}-7(9.23 \mathrm{e}-8)$ & $9.04 \mathrm{e}-7(9.23 \mathrm{e}-8)$ \\
CP & $1.67 \mathrm{e}-7(1.47 \mathrm{e}-04)$ & $1.78 \mathrm{e}-7(1.47 \mathrm{e}-04)$ & $1.78 \mathrm{e}-7(9.34 \mathrm{e}-05)$ \\
ATP & $5.1 \mathrm{e}-5(0.000109)$ & $1.86 \mathrm{e}-4(0.000198)$ & $1.87 \mathrm{e}-4(0.000402)$ \\
ASP & $5.1 \mathrm{e}-5(0.000109)$ & $1.86 \mathrm{e}-4(0.000198)$ & $1.87 \mathrm{e}-4(0.000402)$ \\
P & $4.7 \mathrm{e}-5(7.88 \mathrm{e}-5)$ & $1.00 \mathrm{e}-4(9.55 \mathrm{e}-5)$ & $1.00 \mathrm{e}-4(1.19 \mathrm{e}-4)$ \\
PP & $1.08 \mathrm{e}-5(1.09 \mathrm{e}-05)$ & $9.96 \mathrm{e}-5(1.03 \mathrm{e}-04)$ & $1.00 \mathrm{e}-4(1.03 \mathrm{e}-04)$ \\
AMP & $1.08 \mathrm{e}-5(1.00 \mathrm{e}-05)$ & $9.96 \mathrm{e}-5(7.63 \mathrm{e}-05)$ & $1.00 \mathrm{e}-4(7.63 \mathrm{e}-05)$ \\
F & $9.97 \mathrm{e}-5(7.89 \mathrm{e}-05)$ & $9.97 \mathrm{e}-5(8.36 \mathrm{e}-05)$ & $1.00 \mathrm{e}-4(8.36 \mathrm{e}-05)$ \\
U & $1.2 \mathrm{e}-5(1.56 \mathrm{e}-05)$ & $2.20 \mathrm{e}-3(0.0012)$ & $3.77 \mathrm{e}-3(0.0018)$ \\
\hline
\end{tabular}




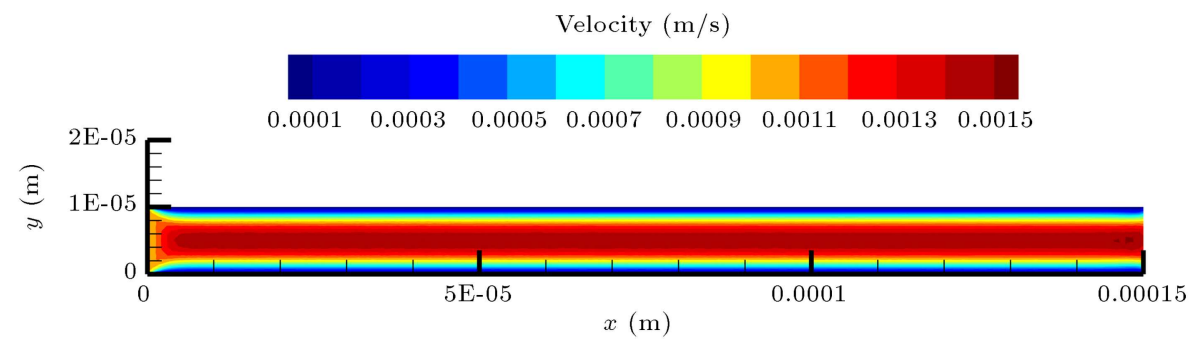

Figure 10. Velocity distribution in the microfluidic channel.

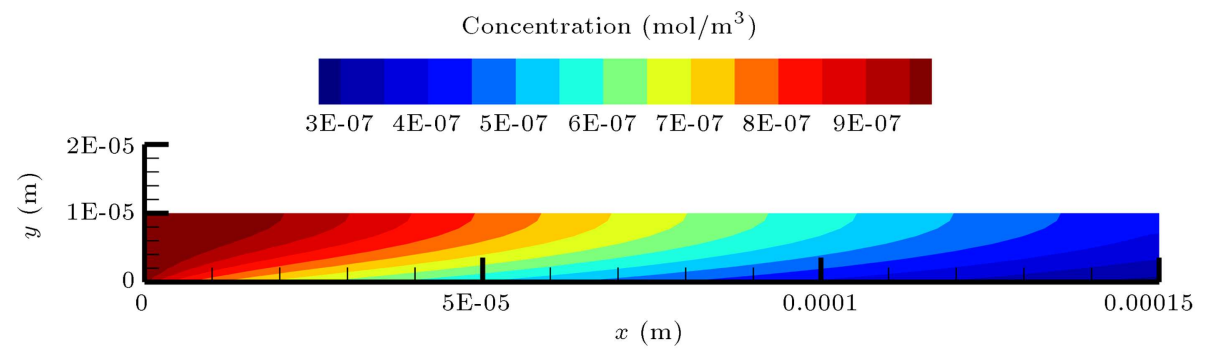

Figure 11. Concentration distribution of ammonia in the microchannel at $t=200 \mathrm{~s}$.

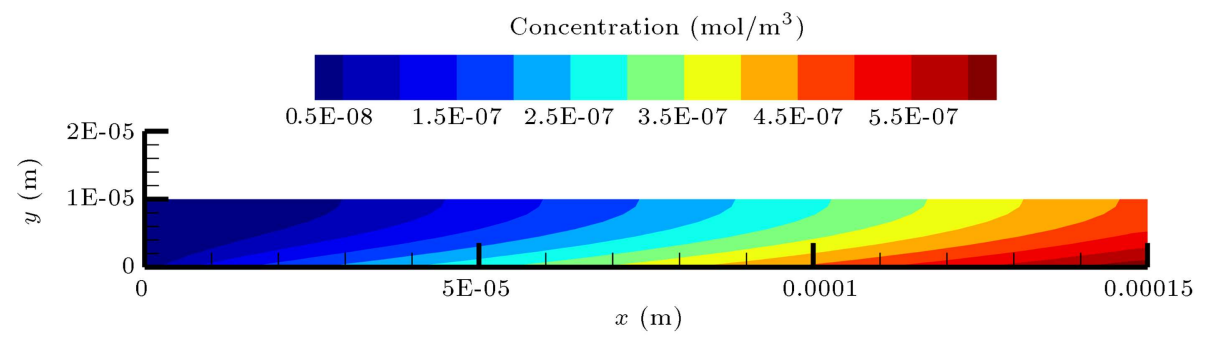

Figure 12. Concentration distribution of urea in the microchannel at $t=200 \mathrm{~s}$.

the flow is viscous dominant; therefore, the developing region is very small.

In the micro channel, ammonia enters the hepatocytes and reacts with its related metabolites. Then, urea is generated within hepatic cells and excreted into the microfluidic device. Resulted distributions of ammonia and urea concentration are presented in Figures 11 and 12, respectively. The gradual decrease of ammonia and increase of urea concentration is obvious along the length of the micro chamber. Most portion of the ammonia converts to urea at the onset of the channel, i.e., one third of the channel length. This fact is in parallel with hepatic zonation in which ureagenesis takes place in the upstream part of sinusoid [21].

Concentration of the urea across the width of the channel is computed using the following equation:

$$
C(x, t)=\int_{0}^{W} c(x, y, t) d y .
$$

Urea concentration along porto central axis, shown in Figure 13, increases with respect to time. Concentration of urea production versus time for a

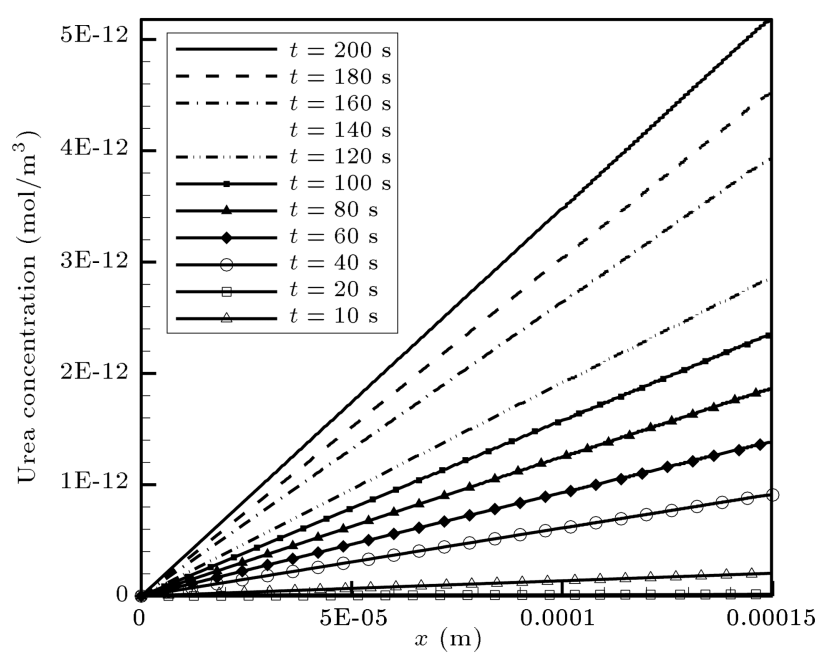

Figure 13. Urea concentration variation along the channel at different times.

single hepatocyte is also shown in Figure 14(f), too. Urea concentration in a cell reaches a plateau in about $300 \mathrm{~s}$ so that the cumulative concentration of the urea along the length of the channel can increase with respect to time and length. 


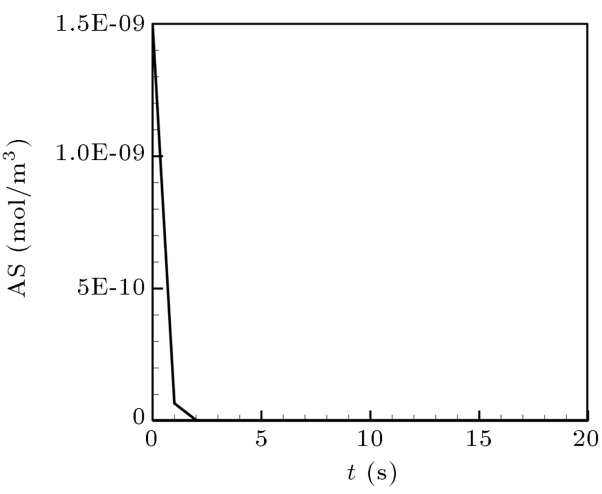

(a)

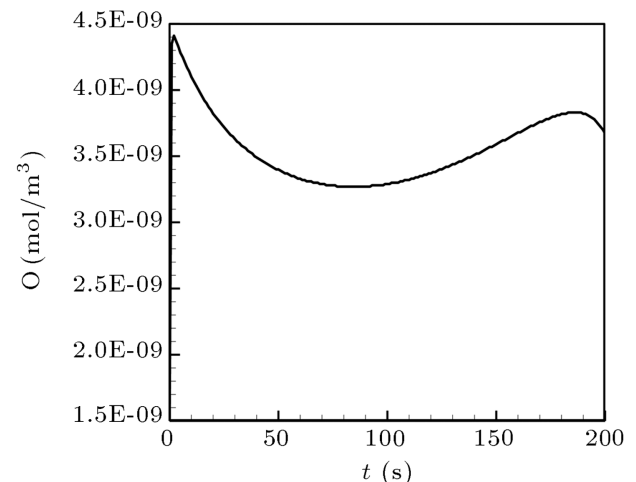

(c)

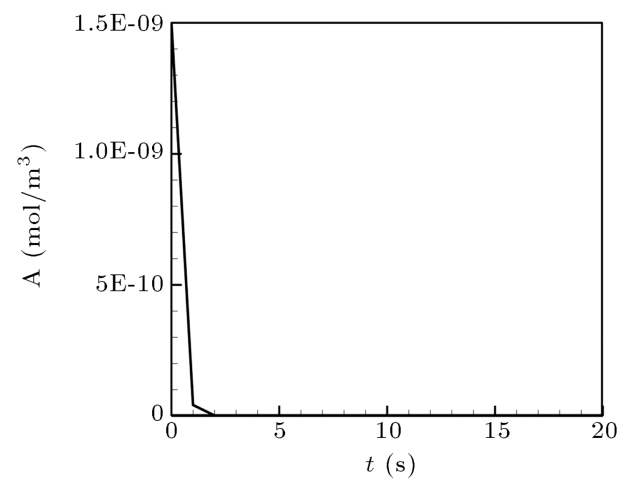

(e)

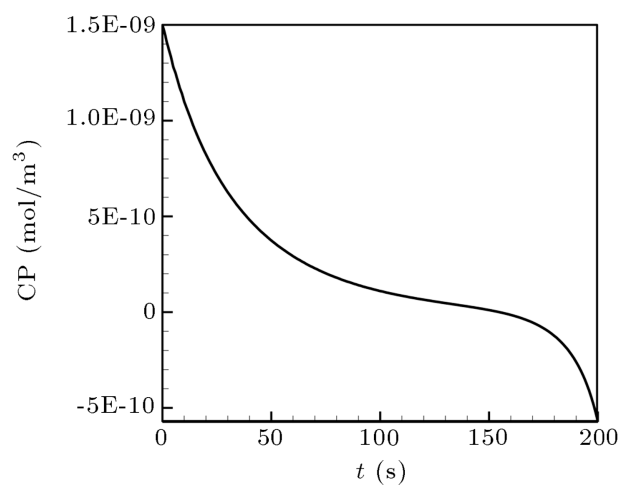

(b)

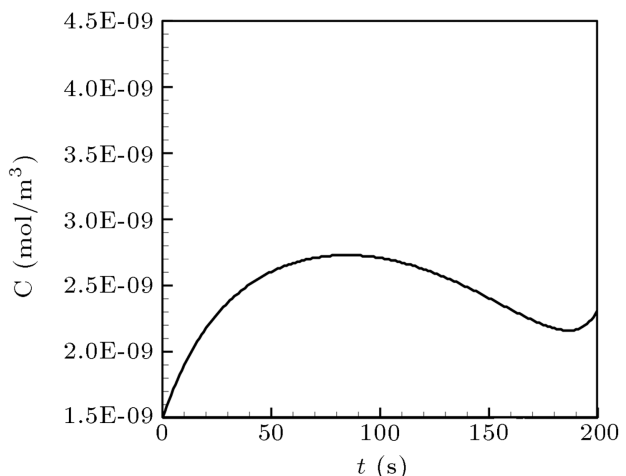

(d)

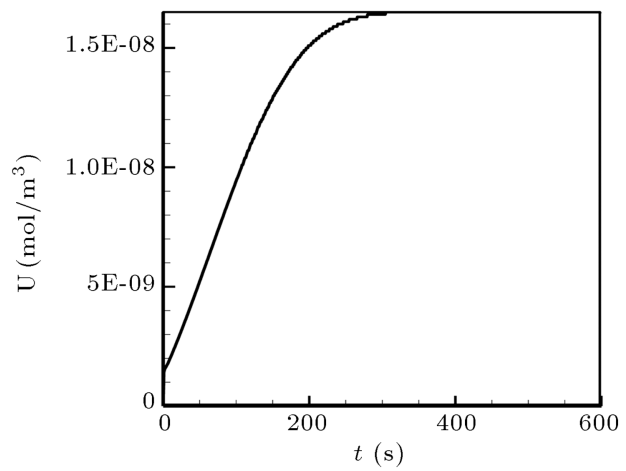

(f)

Figure 14. Variation of some of metabolites concentration versus time.

With the aid of this model, variation of twelve metabolites participating in the urea cycle is obtained, some of which are depicted in Figure 14(a)-(f). Argininosuccinate and carbamoyl phosphate decline corresponding to a monotones increase in urea concentration up until $200 \mathrm{~s}$. Ornithine and citrulline exhibit a nearly opposite flux pattern. In the first $100 \mathrm{~s}$ of simulation, ornithine decreases and, then, increases to amount of about $3.5 \mathrm{e}-4 \mathrm{~mol} / \mathrm{m}^{3}$. Quite the contrary, concentration of citrulline is seen to increase in the span of $100 \mathrm{~s}$ followed by a declination. This concentration then experiences a mild increase to amount of about $2.5 \mathrm{e}-9 \mathrm{~mol} / \mathrm{m}^{3}$. Arginin undergoes a sharp decrease and reaches its minimum amount in a very short amount of time.
Each metabolite has a substantial role in ureagenesis and, if, for any reason, the concentration of metabolites or enzymes changes, ammonia cannot be removed from the blood circulation system. Accordingly, complete lack of each enzyme participating in urea cycle will cause ammonia accumulation in the body and lead to death during the first days of infant's life [18]. The presented model is very useful in predicting the deficiencies encountered in urea cycle and envisaging the consequence of drugs (i.e., sodium phenylacetate and sodium benzoate) and their side effects on the function of this cycle.

For this reason, some of the urea cycle's deficiencies are investigated, and the respective plots are illustrated in Figures 15 to 18, indicating the ratio 


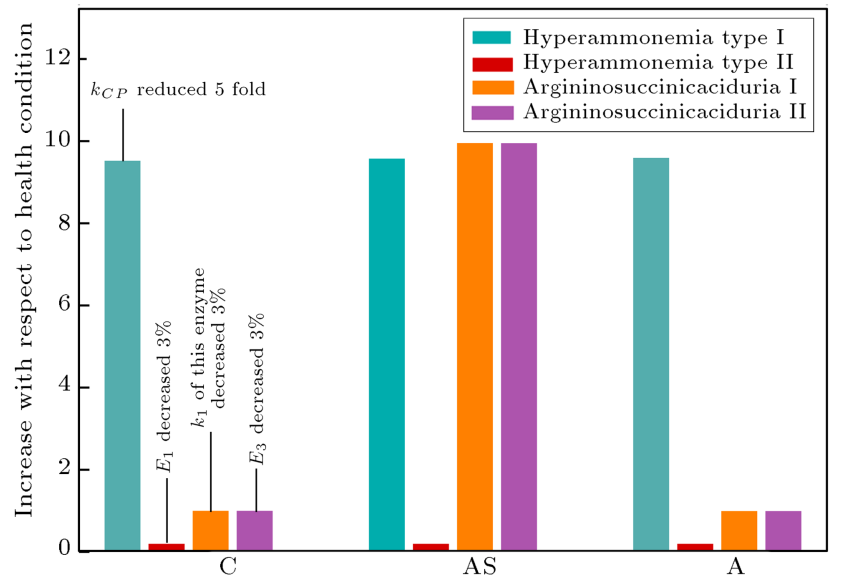

Figure 15. Increase of citrulline, argininosuccinate and arginin due to hyperammonemia types I and II, argininosuccinicaciduria types I and II.

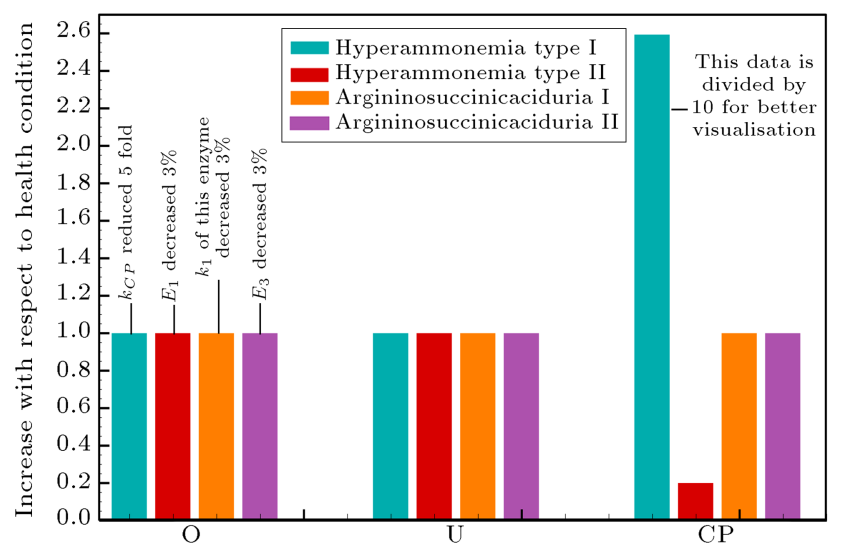

Figure 16. Increase of ornithine, urea and carbamoyl phosphate due to hyperammonemia types I and II, argininosuccinicaciduria types I and II.

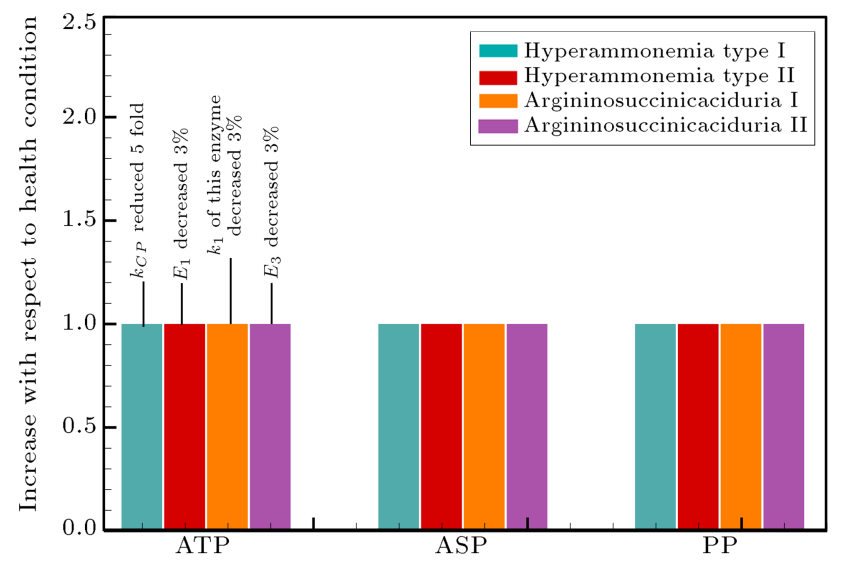

Figure 17. Increase of adenosine triphosphate, aspartate and pyrophosphate due to hyperammonemia types I and II, argininosuccinicaciduria types I and II.

of the metabolites acquired in unhealthy state versus their respected amount in the normal state. At first, hyperammonemia types I and II are considered, which

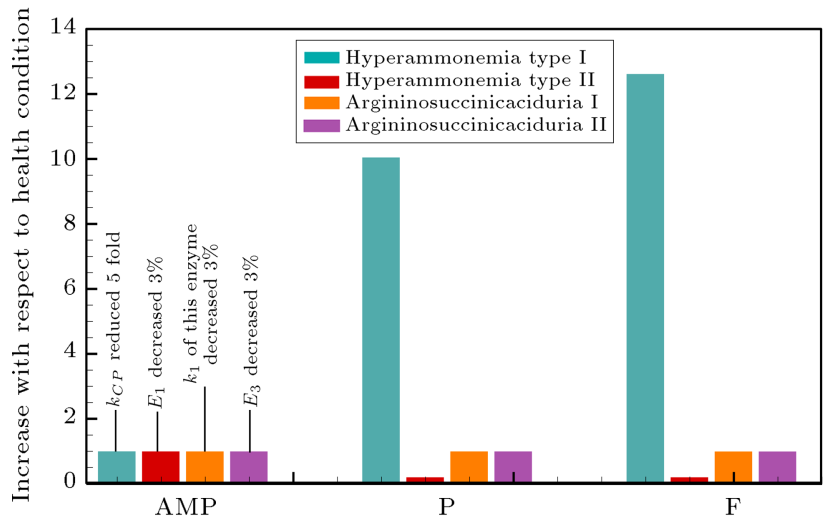

Figure 18. Increase of adenosine monophosphate, fumarate and phosphate due to hyperammonemia types I and II, argininosuccinicaciduria types I and II.

are caused by metabolic block in either the first or second step of the urea cycle [18]. Patients with hyperammonemia type I usually suffer from elevated ketoacidosis (related to metabolic state in which an elevation in ketone metabolites is noticed), neutropenia increase (neutrophils decrease), intermittent hepatomegaly (enlarged liver), and SGOT increase (serum glutamic oxaloacetic transaminase) [18]. Oral administration of ornithine and citrulline is also reported to cause hyperammonemia [22]. Hyperammonemia type I, caused by a disorder in carbamoyl phosphate synthetase, is accompanied by a 5 -fold reduction in the forward kinetic constant of this enzyme [18]. This deficiency is associated with a sharp increase in carbamoyl phosphate concentration (a 25-fold increase). Since the participation of this enzyme is reduced, the metabolite is not present and carbamoyl phosphate concentration increases. Hyper citrullinemia is another aftereffect of this disease. This study predicts an increase in the concentration of citrulline up to circa 10 fold. Freeman et al. [23] and Gatfield et al. [24] also remarked that cabamoylphosphosphate enzyme's deficiency would lead to an increase in urine Ornithine. Pursuant to Figure 16, this simulation predicts no Ornithine imbalance. Due to scarce available information on this area and difficulties in getting samples from patients, usually infants, ornithine concentration in hepatic vein under the effect of hyperammonemia is not reported, and the comparison of the obtained data cannot be made in an allowable manner.

Hyperammonemia type II is the consequence of a $3 \%$ increase in activity of ornithine transcarbamylase [18]. Although urea production appears to be normal, this deficiency causes an $80 \%$ reduction in the concentration of citrulline, argininosuccinate, arginin, carbamoyl phosphate, phosphate, and fumarate. According to many studies' reports, the ammonia concentration in plasma or in urine may change due to urea disorders [24], and the alteration of other metabolites 
probably due to the difficulties in measuring different metabolites behavior remained unsaid.

The next study is carried out on the third enzymes on the urea cycle, i.e., argininosuccinate lyase. Insufficiency of this enzyme would lead to an increase in argininosuccinic acid in the body. The excess excretion of argininosuccinic acid in urea induces argininosuccinicaciduria [25]. A 10\% increase in Michaelis constant of argininosuccinase is caused by argininosuccinicaciduria type I. This deficiency is also one of the congenital diseases that results in accumulation of the ammonia in the body. The predicted outcome results in a 10-fold increase of argininosuccinate concentration, while other metabolite's concentration remains nearly unchanged. The increase of carbamoyl phosphate concentration is not noteworthy; thus, hyperammonemia is not threatening herein, as it was mentioned in $[2,18]$. Argininosuccinicaciduria type II is followed by a reduction in the activity of arginase at about $3 \%$. The metabolite concentration of this condition is nearly similar to that of argininosuccinicaciduria type I except that type II concentration is a bit higher.

\section{Conclusion}

Liver, due to its numerous functions, plays a substantial role in human's life. One of its pivotal functions is ammonia detoxification. Liver removes blood ammonia through the urea cycle. In this study, a model of ureagenesis in one sub-branch of the liver, sinusoid, was simulated in which rough structural forms of hepatocytes in sinusoids were considered. The hepatocytes were aligned in a monolayer arrangement at the bottom of the microfluidic devices. The model succeeded in representing the metabolic heterogeneity of ammonia detoxification along the liver sinusoids, presenting a close resemblance to the actual hepatic sinusoids inside the human body.

Fluid velocity and convection diffusion equations were solved in a micro channel. Ammonia elimination and urea production were modelled via a four-enzyme simulation in a sub cellular level. Results were in good agreement with previous experimental data, showing a 25-fold increase of carbamoyl phosphate concentration in hyperammonemia type I. An $80 \%$ reduction in the concentration of citrulline, argininosuccinate, arginin, carbamoyl phosphate, phosphate, and fumarate was observed in hyperammonemia type II, and a 10-fold increase of argininosuccinate concentration was accompanied by both argininosuccinicaciduria types I and II.

This paper presented a novel model system consisting simultaneously of modelling of ureagenesis in intra and extra cellular levels by considering related rate reactions and structure of hepatic lobule. By means of this simulation, the study of biological entities affecting urea cycle and ammonia detoxification is possible. The predicted results are useful in better understanding, controlling, and managing the effects of metabolite deficiencies, drugs, and their side effects on the overall metabolic behavior in hepatocytes' urea cycle.

\section{Acknowledgment}

We gratefully acknowledge the financial support (Grant\# G940502) from Deputy of Research office of Sharif University of Technology.

\section{References}

1. Guyton, A.C. and Hall, J.E., Text Book of Medical Physiology, 11th Edn. pp. 830-864, Elsevier Saunders, Philadelphia, USA (2006).

2. Kuchel, P.W., Roberts, D.V., and Nichol, L.W. "The simulation of urea cycle: correlation of effects due to inborn errors in the catalytic properties of the enzymes with clinical-biochemical observations", Aust. J. Exp. Biol. Med. Sci., 55(3), pp. 309-326 (1977).

3. Kohn, M.C., Tohmaz, A.S., Giroux, K.J., Blumenthal, G.M., Feezor, M.D., and Millington, D.S. "Robustness of MetaNet graph models: predicting control of urea production in humans", BioSystems, 65(1), pp. 61-78 (2002).

4. Maher, A.D., Kuchel, P.W., Ortega, F., Atauri, P., Centelles, J., and Cascante, M. "Mathematical modeling of the urea cycle: a numerical investigation into substrate channeling", Eur. J. Biochem., 270(19), pp. 3953-3961 (2003).

5. Ohno, H., Naito, Y., Nakajima, H., and Tomita, M. "Construction of a biological tissue model based on a single-cell model: a computer simulation of metabolic heterogeneity in the liver lobule", Artif. Life, 14(1), pp. 3-28 (2008).

6. Prodanov, L., Jindal, R., Sundhar Bale, S., Manjunath Hegde, M., McCarty, W.J., Golberg, I., Bhushan, A., Yarmush, M.L., and Usta, O.B. "Long term maintenance of a microfluidic 3-D human liver sinusoid", Biotechnol Bioeng., 113(1), pp. 241-246 (2016).

7. Materne, E., Tonevitsky, A.G., and Marx, U. "Chipbased liver equivalents for toxicity testing - organotypicalness versus cost-efficient high throughput", Lab on a Chip, 18, pp. 3481-3495 (2013).

8. Ahmadian, M.T., Firoozbakhsh K., and Hasanian, M. "Simulation of red blood cell motion in microvessels using modified moving particle semi-implicit method", Scientia Iranica, 19(1), pp. 113-118 (2012).

9. Navidbakhsh, M. and Rezazadeh, M. "An immersed boundary-lattice Boltzmann model for simulation of malaria-infected red blood cell in micro-channel", Scientia Iranica, 19(5), pp. 1329-1336 (2012).

10. Schmidt, R.F. and Thews, G., Human Physiology, Translated by Marguerite A. Biederman-Thorson, 2nd Edn., pp. 640-650, Springer-Verlag, Berlin, Germany (1989). 
11. White, F.M., Viscous Fluid Flow, 3rd Edn., pp. 59-205, McGraw Hill, New York, USA (2006).

12. Bird, R.B., Stewart, W.E., and Lightfoot, E.N., Transport Phenomena, 2nd Edn., pp. 514-568, John Wiley and Sons, New York, USA (1976).

13. Rodés, J., Benhamou, J., Blei, A.T., Reichen, J., and Rizzetto, M., Text Book of Hepatology: From Basic Science to Clinical Practice, 3rd Edn., pp. 182-188, Wiley-Black Well, Massachussetts, USA (2007).

14. Stoker, S.H., Organic and Biological Chemistry, 6th Edn., pp. 623-624, Cengage Learning, California, USA (2012).

15. Schimke, R.T. "Adaptive characteristics of urea cycle enzymes in the rat", J. Biol. Chem., 237, pp. 459-468 (1962).

16. Schimke, R.T. "Studies on factors affecting the levels of urea cycle enzymes in rat liver", J. Biol. Chem., 238, pp. 1012-1018 (1963).

17. Nuzum, C.T. and Snodgrass, P.J. "Urea cycle enzyme adaptation to dietary protein in primates", Science, 172(3987), pp. 1042-1043 (1971).

18. Shih, V.E. and Efron, M.L. "Urea cycle disorders", In The Metabolic Basic of Inherited Disease, J.B. Stanbury, J.B. Wyngaarden, and D.S. Fredrikson, 3rd Edn., pp. 370- 392, McGraw-Hill, US (1972).

19. Mulquiney, P.J. and Kuchel, P.W., Modeling Metabolism with Mathematica, pp. 93-99, CRC Press, Boca Raton, US (2003).

20. MacPhee, P.J., Schmidt, E.E., and Groom, A.C. "Intermittence of blood flow in liver sinusoids, studied by higher-solution in vivo microscopy", Am. J. Physiol., 269(5) pp. 692-698 (1995).

21. Gebhardt, R. and Matz-Soja, M. "Liver zonation: Novel aspects of its regulation and its impact on homeostasis", World J. Gastroenterol., 20(26), pp. 8491-8504 (2014).

22. Freeman, J.M., Nicholson, J.F., Schimke, R.T., Rowland, L.P., and Carter, S. "Congenital hyperammonemia: association with hyperglycinemia and decreased levels of carbamoyl phosphate synthetase", Arch. Neurol., 23(5), pp. 430-437 (1970).

23. Gatfield, P.D., Taller, E., Wolfe, D.M., and Haust, M.D. "Hyperornithinemia, hyperammonemia, and homocitrullinuriaassociated with decreased carbamoyl phosphate synthetase1 activity", Pediatr. Res., 9(5), pp. 488-497 (1975).

24. Serrano, M., Ormazábal, A., Vilaseca, M.A., Lambruschini, N., Garcia-Romero, R., Meavilla, S., Perez-
Dueñas, B., Pineda, M., Garcia-Cazorla, A., Campistol, J., and Artuch, R. "Assessment of plasma ammonia and glutamine concentrations in ureacycle disorders", Clin. Biochem., 44(8-9), pp. 742-744 (2011).

25. Erez, A., Nagamani, S.C.S., and Lee, B. "Argininosuccinate lyase deficiency - Argininosuccinic aciduria and beyond", Am. J. Med. Genet. C Semin Med. Genet., $\mathbf{1 5 7}(1)$, pp. 45-53 (2011).

\section{Biographies}

Fatemeh Sharifi is a $\mathrm{PhD}$ student in the School of Mechanical Engineering at Sharif University of Technology, Tehran, Iran. She spent almost two years at Harvard-MIT division of health Sciences and Technology where she worked on organ-on-a-chip and bioprinting. Her research interests include biomechanics, lab-on-a-chips, microfluidics, biomaterials, and regenerative engineering.

Bahar Firoozabadi received her $\mathrm{PhD}$ in Mechanical Engineering from Sharif University of Technology, Tehran, where she is now a Professor at the related Department. Her research interests include fluid mechanics in density currents, presently focusing on biofluid mechanics. She teaches fluid mechanics and gas dynamics to undergraduates, and viscous flow, advanced fluid mechanics, continuum mechanics and biofluid mechanics to graduate students.

Mohammad Said Saidi is a Professor of Mechanical Engineering at Sharif University of Technology. His research interests are modeling and numerical analysis of transport and deposition of aerosol particles, modeling and numerical analysis of biofluids, modeling and numerical analysis of thermal-hydraulics of porous media and microchannels.

Keikhosrow Firoozbakhsh is a Professor of Mechanical Engineering at Sharif University of Technology. He received his $\mathrm{PhD}$ and $\mathrm{MS}$ at Wayne State University, Detroit, Michigan, USA. His research area is theoretical applied mechanics, and bioengineering. He spent one year at Tulane University, New Orleans, USA as a post doctorate and worked on bone mechanics. Courses taught were plate and shell, elasticity, visco-elasticity, thermos-elasticity, continuum mechanics, biomechanics of muscular skeleton system, and principles of bioengineering. 